\title{
Fatigue and Healing Properties of Low Environmental Impact Rubberized Bitumen for Asphalt Pavement
}

\author{
Ayad Subhy and Davide Lo Presti * \\ Nottingham Transportation Engineering Centre, University of Nottingham, University Park, \\ Nottingham NG7 2RD, UK; ayad.subhy@nottingham.ac.uk \\ * Correspondence: davide.lopresti@nottingham.ac.uk; Tel.: +44-115-8467-993
}

Academic Editors: Andrea Simone and Claudio Lantieri

Received: 21 March 2017; Accepted: 29 April 2017; Published: 5 May 2017

\begin{abstract}
The addition of recycled tyre rubber as a modifier to enhance the mechanical properties of bitumen has proven to provide asphalt mixtures with better mechanical performance. However the rubberised bitumen presents the limitation of requiring higher manufacturing and compaction temperatures. This could be solved by subjecting the tyre rubber to sort of pre-treatments such as: Adding warm-mix additives and/or using partial devulcanisation. These solutions have the potential of lowering the overall environmental impact of the asphalt pavement, however it is still not clear whether these can be detrimental for the rubberized asphalt binder mechanical properties. This paper investigates the effect on fatigue and healing properties of rubberized bitumen blended with pre-treated crumb rubber. An innovative combined fatigue and healing analysis will be presented and used to compare the several rubberised binders with a neat bitumen. The analysis consists in conducting time sweep tests by means of dynamic shear rheometer, by applying repeated cycles of stress or strain loading at selected temperatures and loading frequency. The healing potential of binders was evaluated by introducing short rest periods after a certain number of load pulses. At last, the unique energy parameter obtained using the Ratio of Dissipated Energy Change approach, was applied to obtain a unique index that could provide combined information for both fatigue binder damage and healing phenomenon. The results showed that the analysed rubberised bitumens show having better fatigue and healing performance when compared to the straight-run bitumen.
\end{abstract}

Keywords: rubberised bitumen; pre-treated crumb rubber; fatigue; healing

\section{Introduction}

The addition of recycled tyre rubber to the conventional bituminous materials has shown improved fatigue and rutting characteristics and, consequently, the road surface is expected to have longer service life and needs lower maintenance/repair costs [1-4]. It is well known that fatigue resistance of hot-mix asphalt (HMA) mixtures is significantly related to the properties of their bituminous binders and cracking usually starts and propagates within the binder. Thus, it is important to modify the base bitumen and evaluate the modifier effect on the fundamental and functional properties. However, the characterization of binders should be based on test methods and parameters that can reliably rate the binder contribution to fatigue damage resistance. Many studies have suggested that the Strategic Highway Research Program (SHRP) fatigue parameter $\left(G^{*} \cdot \sin \delta\right)$ does not reflect the true binder performance related to asphalt mixture or pavement performance [5-10]. On the other hand, the time sweep repeated cyclic loading using dynamic shear rheometer (DSR) allows the fatigue phenomenon to be simulated and monitored directly. This method defines well the fatigue characteristic of binders and is strongly correlated with asphalt mixture and long-term pavement performance [6]. The dissipated energy approach has been also successfully applied for fatigue analysis and can provide an intrinsic fatigue law for bituminous materials [11-14]. It gives the 
inherent resistance of the material to fatigue cracking and it is hypothesized to be independent of the mode of loading. The test also allows evaluating the healing potential of binders by introducing rest periods among the continuous loading sequence in fatigue test [15-18].

This study aims at improving the performance related properties of the conventional bituminous materials by the addition of different recycled tyre rubbers. The fatigue properties and healing phenomenon were characterized using the dissipated energy approach. The two different recycled tyre rubber were surface activated rubber particles; the first recycled rubber was activated by special oil and Fischer-Tropsch wax (Sasobit ${ }^{\circledR}$, Hamburg, Germany), and the second was a partly devulcanised recycled rubber.

\section{Materials and Methods}

\subsection{Materials}

It is well known that manufacturing asphalt mixes with Recycled Tyre Rubber Modified Bitumen (RTR-MBs) requires higher temperatures due to their increased High Temperature viscosity (HTV). This can cause not desirable emission problems and further harden the asphalt [19]. Many studies have been done to produce RTR-MBs that have reduced HTV and/or extended shelf life characteristics [20-25]. However, limited studies have considered using pre-treated recycled rubber with warm-mix technology additives (WMA) or using devulcanised rubber to allow better workability and handling. In this study, the RTR-MBs were prepared by two different pre-treated recycled rubbers and one base binder; the first recycled rubber was activated by special oil and Fischer-Tropsch wax (Sasobit ${ }^{\circledR}$ ), and the second was a partly devulcanised recycled rubber. A straight-run bituminous binder has a penetration of $200 \mathrm{dmm}$ and a softening point of $37^{\circ} \mathrm{C}$ was used in this study. Two different pre-treated recycled rubbers RTRs were used in this study labelled as TRD and TRSE. TRD is also recycled from truck and passenger car tyres by ambient grinding but contains $20 \%$ devulcanised rubber. The devulcanisation was based on mechano-chemical processes in which the sulphur cross links in the polymer chain were uncoupled, but its chemical composition was not changed. The process of devulcanisation the crumb rubber was conducted in a close system at which the level of contaminated fumes and unpleasant odours were significantly reduced. TRSE consists of $100 \%$ recycled truck tyres which by nature have a relatively high content of natural rubber. TRSE is pre-treated with special oil and FT-wax component. The FT-wax component in TRSE allows a reduction in mixing temperature, without running the risk of insufficient workability and compactability. Figure 1 shows the percent passing gradation of rubber particles. The recycled tyre rubber modified bitumen (RTR-MBs) was manufactured by the wet process method. The straight-run binder was preheated to $180{ }^{\circ} \mathrm{C}$ and then $18 \%$ of recycled tyre rubber by the weight of base bitumen was added gradually to the binder while mixing at $180^{\circ} \mathrm{C}$ using a Silverson L4RT high shear laboratory mixer (Chesham, UK) for $140 \mathrm{~min}$. Other physical and rheological properties of the straight-run binder and RTR-MBs are presented in Table 1. STRD and STRSE are the names of RTR-MBs processed using the straight-run binder " $\mathrm{S}$ " with the recycled tyre rubbers TRD and TRSE, respectively, as described in Table 2 . The effect of ageing was not considered in this study, all fatigue and healing tests were conducted on unaged binders at the University of Nottingham's laboratory.

\subsection{Experimental Design}

The time sweep binder fatigue test was performed using Kinexus Model Dynamic Shear Rheometer (DSR, Malvern, UK). This model of DSR uses a Peltier system (Malvern, UK) to control the temperature unlike other DSRs that use a water bath which could have an effect on the fatigue process. All tests were carried out under controlled stress conditions and at a frequency of $10 \mathrm{~Hz}$ using the $8 \mathrm{~mm}$ plate-plate set-up and $2 \mathrm{~mm}$ gap. The testing temperature was selected as $0{ }^{\circ} \mathrm{C}$ to ensure higher initial complex modules $\left|\mathrm{G}^{*}\right|$ (larger than $25 \mathrm{MPa}$ ) so that the edge effects or plastic flow can be eliminated and the binders fail due to "true" fatigue damage rather than "instability flow" [26]. At these conditions there was no gradual decrease noticed in the radius of the sample after fatigue 
test, the failure was due to complete fracture through the whole sample as can be seen in Figure 2 . Various stress levels between 160 and $500 \mathrm{kPa}$ were applied on the different binders to induce different initial strains range from $0.5 \%$ to $1.5 \%$. To investigate the effect of rest periods (healing) on bitumen fatigue, an intermittent loading sequence was used by introducing short constant rest periods (10 and $20 \mathrm{~s}$ ) after every 500 load pulses. Using the intermittent loading sequence is believed to provide better simulation of field loading conditions compared with other loading sequences in which a single long stop period is used [18].

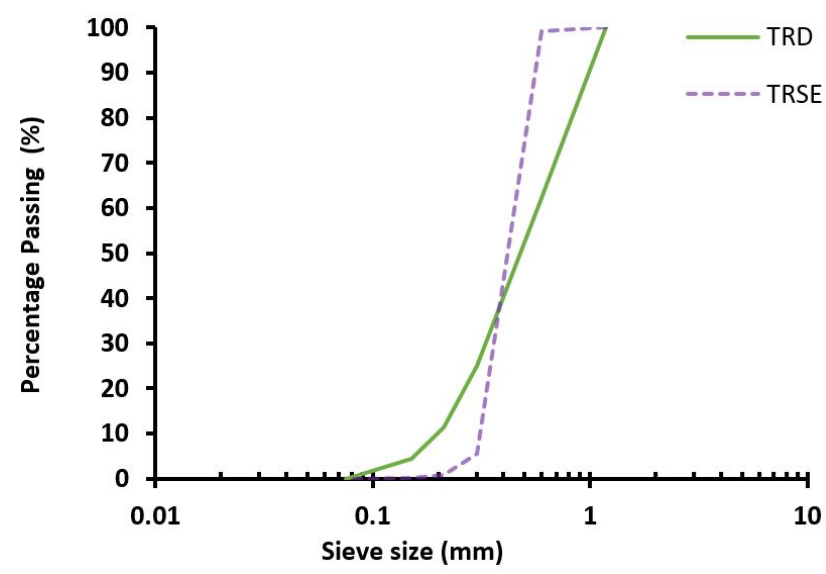

Figure 1. The passing percent gradation of RTRs.

Table 1. The properties of base binder and RTR-MBs used in this study.

\begin{tabular}{clccc}
\hline \multirow{2}{*}{ Ageing States } & \multicolumn{1}{c}{ Index } & $\begin{array}{c}\text { Straight-Run } \\
\text { Binder }\end{array}$ & STRD & STRSE \\
\hline \multirow{3}{*}{ Unaged binder } & Penetration $@ 25{ }^{\circ} \mathrm{C}, 0.1 \mathrm{~mm}$ & 200 & - & - \\
\cline { 2 - 5 } & Softening point ${ }^{\circ} \mathrm{C}$ & 37.0 & - & - \\
\cline { 2 - 5 } & Rotational viscosity, $\mathrm{mPa} \cdot \mathrm{s} @ 180^{\circ} \mathrm{C}$ & 25 & 560 & 355 \\
\cline { 2 - 5 } & Asphaltenes content & $4.2 \%$ & - & - \\
\cline { 2 - 5 } & $\left|\mathrm{G}^{*}\right| / \sin \delta @ 60^{\circ} \mathrm{C} \& 1.59 \mathrm{~Hz}, \mathrm{kPa}$ & 0.615 & 6.053 & 12.13 \\
\hline RTFOT or TFOT * aged residue & $\left|\mathrm{G}^{*}\right| / \sin \delta @ 60^{\circ} \mathrm{C} \& 1.59 \mathrm{~Hz}, \mathrm{kPa}$ & 1.256 & 12.05 & 25.86 \\
\hline RTFOT or TFOT * + PAV aged residue & $\left|\mathrm{G}^{*}\right| \cdot \sin \delta @ 10^{\circ} \mathrm{C} \& 1.59 \mathrm{~Hz}, \mathrm{kPa}$ & 5650 & 3680 & 4734 \\
\hline
\end{tabular}

* TFOT was used as short-term ageing for the RTR-MBs while RTFOT was used for the straight-run binder.

Table 2. General description of bituminous binders that used in this study.

\begin{tabular}{clc}
\hline No. & \multicolumn{1}{c}{ Material Description } & Code \\
\hline 1 & Neat bitumen Pen 160/220 & Straight run bitumen \\
\hline 2 & $\begin{array}{l}\text { Rubberised bitumen manufactured using } 84.75 \% \text { of neat } \\
\text { bitumen Pen } 160 / 220 \text { with } 15.25 \% \text { of TRD crumb rubber }\end{array}$ & STRD \\
\hline 3 & $\begin{array}{l}\text { Rubberised bitumen manufactured using } 84.75 \% \text { of neat } \\
\text { bitumen Pen 160/220 with 15.25\% of TRSE crumb rubber }\end{array}$ & STRSE \\
\hline
\end{tabular}

\section{Results and Discussion}

\subsection{Traditional Fatigue Analysis}

The fatigue analysis is traditionally expressed by the so called "WÖHLER" curve. This curve shows the relation between the fatigue life $N_{f}$ and the applied initial stress or strain using the power fatigue law as follows:

$$
N_{f}=a\left(\varepsilon_{o}\right)^{b}
$$


where $N_{f}=$ number of cycles to failure, $\varepsilon_{o}=$ initial strain, $a$ and $b$ are experimentally determined constants. It was noticed that the initial strains have the most significant effect on fatigue life, therefore, the average strains during the first 1000 cycles from stress controlled tests were selected as representative initial strain in Equation (1). The number of cycles to failure $N_{f}$ was determined from the evolution of phase angle versus complex modulus (black diagram), see Figure 2. Di Benedetto, et al. [27] demonstrated that the black diagram during fatigue evolution is a promising approach to define the stages of fatigue development irrespective of the loading test conditions. The change in the process evolution of the black diagram gives a definitive limit between crack initiation and crack propagation. $N_{f}$ can be defined from the value of phase angle at the intersection of the two straight lines. These lines used to linearize the evolution of phase angles for each period; the $N_{f}$ corresponds to the defined phase angle is then determined as shown in Figure 2. This method can well define the transition point from crack initiation to crack propagation unlike the arbitrary approach of $50 \%$ decrease in the initial stiffness as can be seen in Figure 3a,b. Additionally, many studies have shown that the $50 \%$ decrease in the initial stiffness does not always seem appropriate for analysing fatigue properties $[6,28,29]$. The results in Figures 4 and 5 clearly show that the addition of recycled rubbers significantly enhanced the fatigue resistance of materials. Also, in the case of including $10 \mathrm{~s}$ RP (rest period), it can be seen that there is a considerable increase in fatigue life of RTR-MBs compared to the straight-run bitumen. This indicates that RTR-MBs also have better healing properties than the pure bitumen. When the different pre-treated RTR-MBs are compared, it can be seen that the fatigue curves of both rubberised bitumen in the case of no RP are very close. While in the case of including $10 \mathrm{~s}$ RP, the STRSE had slightly better fatigue behaviour than STRD. This indicates that it is important to characterise the healing properties in addition to fatigue resistance for a proper material selection.

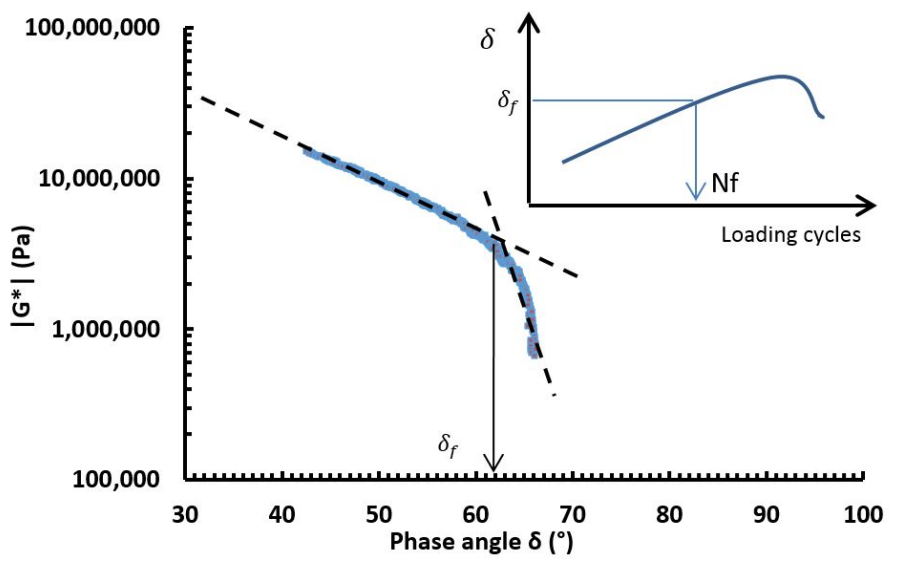

Figure 2. Identify the $\left(N_{f}\right)$ from the evolution of phase angle versus complex modulus (Black Diagram).

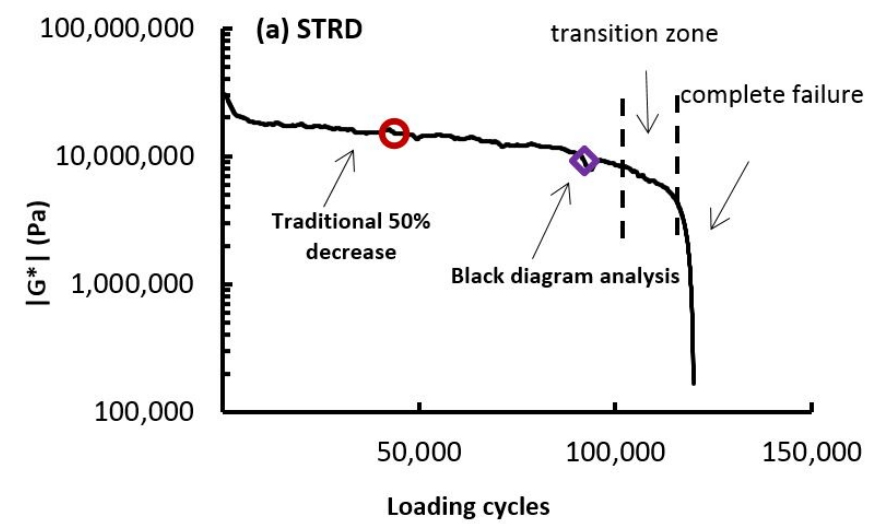

Figure 3. Cont. 


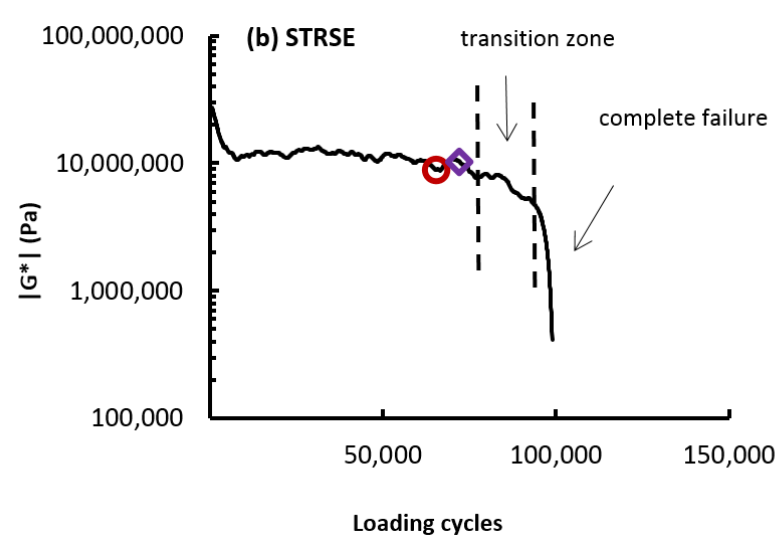

Figure 3. The failure points located at the evolution of $\left|G^{*}\right|$ vs. load cycles during the fatigue test: (a) STRD and (b) STRSE.

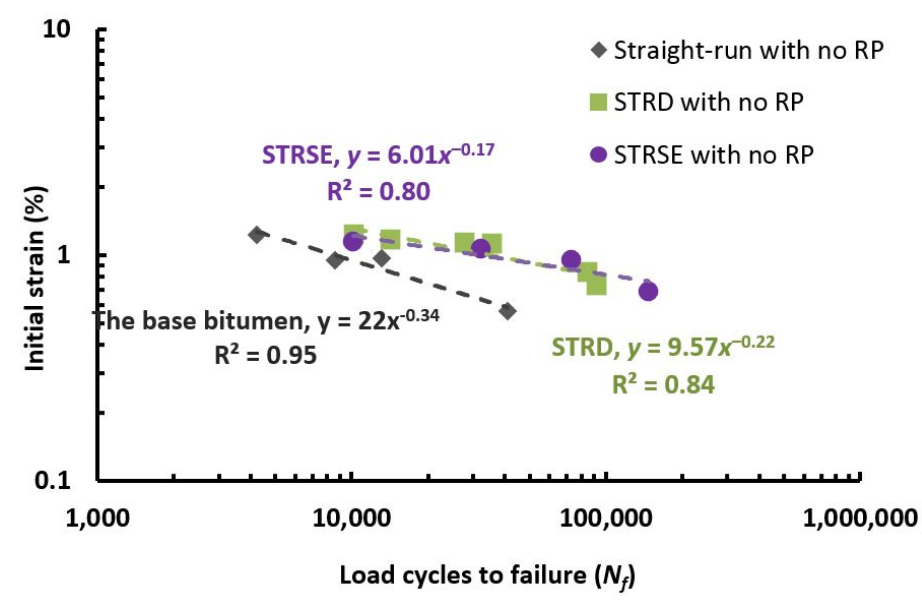

Figure 4. Traditional fatigue curves for all binders with no rest period.

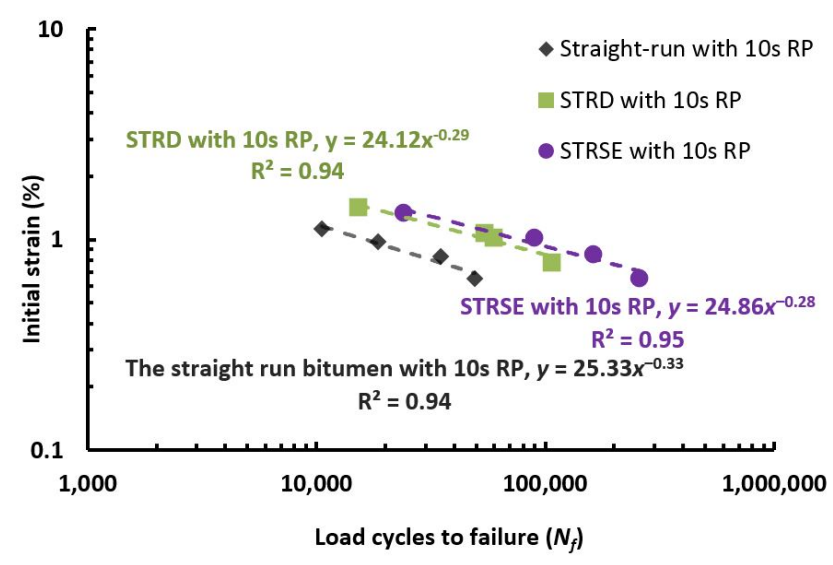

Figure 5. Traditional fatigue curves for all binders with $10 \mathrm{~s}$ rest period.

\subsection{The Dissipated Energy Approach}

The viscoelastic materials when subjected to cyclic loading generate different paths for loading and unloading leading to hysteresis loops. The dissipated energy per cycle is computed as the area within the hysteresis loop and calculated by the following equation:

$$
w_{i}=\pi \sigma_{i} \varepsilon_{i} \sin \delta_{i}
$$


where $\mathrm{w}_{i}=$ the dissipated energy at cycle $i ; \sigma_{i}, \varepsilon_{i}, \delta_{i}=$ the stress amplitude, strain amplitude and phase angle at cycle $i$, respectively. Ghuzlan and Carpenter [14] proposed the Dissipated Energy Ratio (DER) to study the fatigue behaviour. The DER or the Ratio of Dissipated Energy Change (RDEC) approach was then developed by Carpenter and Shen [30] who emphasised the fact that damage will only be generated when there is a difference in dissipated energy between consecutive cycles. RDEC is expressed as:

For controlled stress mode:

$$
R D E C_{i}=\frac{\left(w_{i}-w_{j}\right)}{w_{i} \times(i-j)}
$$

where $R D E C_{i}=$ ratio of dissipated energy change value at cycle $i ; w_{i}$ and $w_{j}=$ dissipated energies at cycles $i$ and $j$; and $i, j=$ loading cycle, $i>j$. Several studies showed that the Plateau Value (PV) which is the value of $R D E C$ at the steady-state phase can provide a unique relationship with the number of loading cycles to failure for different mixtures, loading modes and loading levels $[11,18,30,31]$. The relationship between the (PV) and the number of load cycles to failure was found to be a power law relation as follows [14]:

$$
\mathrm{PV}=c \times N_{f a t}^{d}
$$

where $c$ and $d$ = regression constants; and $N_{f a t}=$ number of load cycles to failure. Applying this approach, the plateau value was computed for all studied binders under different testing conditions (stress levels and rest periods). These (PVs) are then plotted against the defined failure point $\left(N_{f}\right)$, as shown in Figure 6. The results in Figure 6 show that there is a unique power-low relationship between $(\mathrm{PV})$ and $\left(N_{f}\right)$ with acceptable $R^{2} \approx 0.94$ regardless of rest periods, but this relationship is strongly dependent on material type. These PV- $\mathrm{N}_{f}$ curves are contradictory to the other fatigue finding investigated by Shen and her co-workers $[11,18,31,32]$. They showed that this relationship is unique regardless of mixture type. However, considering the results in this study and comparing other fatigue studies conducted by other researchers [11,18,31,33-35], all showed that PV- $N_{f}$ relationship was not the same for materials undertaken in these studies. Accordingly, both RTR-MBs were better fatigue performers than the straight-run bitumen because at a certain amount of relative dissipative energy, $(\mathrm{PV})$, they were able to sustain higher number of fatigue cycles.

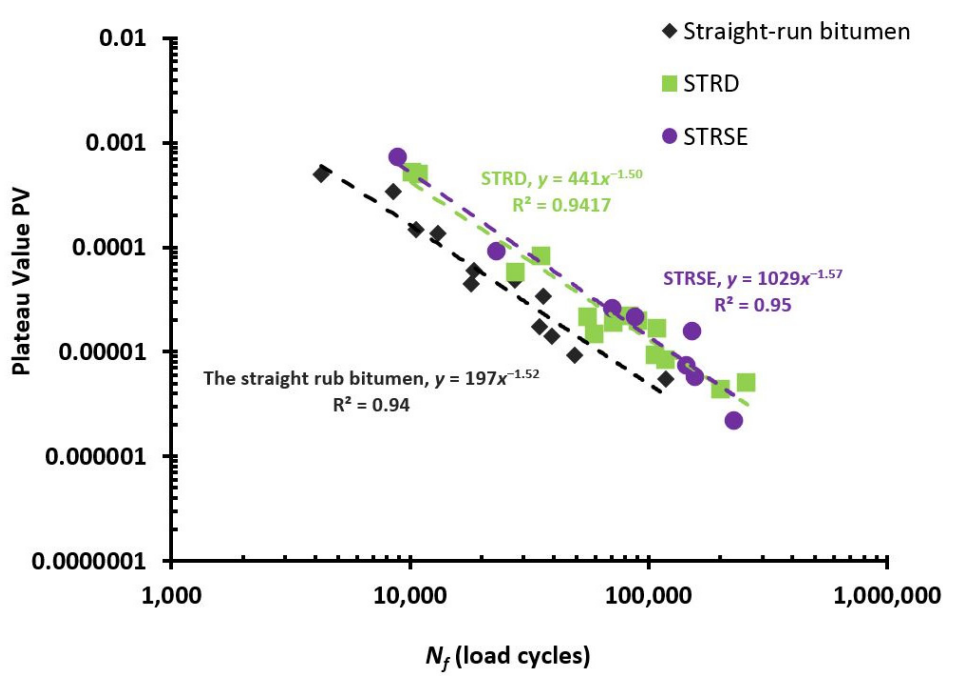

Figure 6. PV vs. $N_{f}$ curves for all binders with/without rest period.

\subsection{Quantifying Healing Properties}

To quantify and evaluate realistically the effect of incorporating different pre-treated rubber types on healing potential, a "like-for-like" study was made. It is well know that initial strain and stress level are the most significant parameters affecting the fatigue and healing properties. Therefore, 
both initial strain and stress level were kept the same for all binders in the "like-for-like" study by conducting the fatigue tests at equi-stiffness conditions. This can only be done by changing the testing temperature so the different binders are investigated at a temperature where the binder stiffness at $10 \mathrm{~Hz}$ is $\left|\mathrm{G}^{*}\right|=25 \mathrm{MPa}( \pm 10 \%)$. Temperature ramp test was carried out at $10 \mathrm{~Hz}$ frequency and $1 \%$ applied strain to determine the equi-stiffness temperature. The sample was conditioned for $15 \mathrm{~min}$ at $0{ }^{\circ} \mathrm{C}$ and then heated up to $5{ }^{\circ} \mathrm{C}$ with a $1{ }^{\circ} \mathrm{C} / \mathrm{min}$ thermal ramp. The equi-stiffness temperatures for the straight-run bitumen, STRD and STRSE were $4,1.5$ and $2{ }^{\circ} \mathrm{C}$, respectively. The stress level was selected as $250 \mathrm{kPa}$ which induces initial strain of $1 \%$ for all tested materials, and $10 \mathrm{~s}$ rest period was used. Shen, Chiu and Huang [18] quantified the healing potential of asphalt binders based on RDEC, the healing rate was defined as the slope of plateau value PV versus the rest time in a log-log curve. In this study, the following healing index based on evaluating the PV of binders with and without the $10 \mathrm{~s} R \mathrm{P}$ is proposed to evaluate the healing capability.

$$
\text { Healing Potential Index }(\mathrm{HPI})=\frac{P V_{\text {no } R P}-P V_{10 s R P}}{P V_{\text {no } R P}} \times \frac{N_{f(10 s)}-N_{f(n o R P)}}{N_{f(n o R P)}}
$$

It can be seen that this index also contains information about the relative increase in fatigue life $\left(N_{f(10 \mathrm{~s})}-N_{f(n o R P)}\right) / N_{f(n o R P)}$ when the $10 \mathrm{~s}$ RP is introduced. Obviously, material with greater HPI should correspond to better healing capability. Figure 7 shows the results of HPI for the straight-run binder and RTR-MBs. The results clearly show that both the RTR-MBs have higher HPI compared to their base binder.

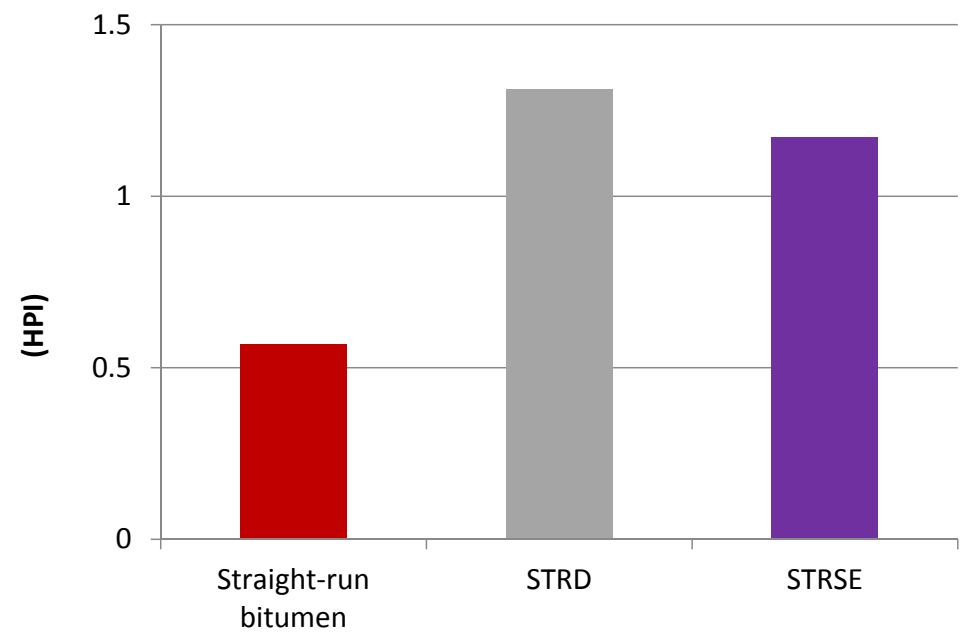

Figure 7. HPI for all binders.

\section{Conclusions}

In this study, the fatigue and healing properties of the straight-run bitumen and RTR-MBs were studied by time sweep repeated cyclic loading tests under stress-controlled condition using oscillatory DSR tests. The fatigue results were analysed based on traditional "WÖHLER" analysis and the Ratio of Dissipated Energy Change (RDEC) approach. The healing capability of binders was evaluated by using a new proposed index. Based on the discussion and analysis described in this paper, the following conclusions and findings can be drawn:

- Using pre-treated RTRs can significantly reduce the High Temperature Viscosity of the binders and this could help lowering manufacturing and compaction temperatures.

- The RTR-MBs manufactured by pre-treated recycled rubbers showed superior fatigue and healing properties over the straight-run bitumen based on both energy and classical fatigue approaches. 
- The healing capability of binders was successfully quantified by the proposed HPI. The index is based on quantifying the relative change in PV multiply by the relative increase in fatigue life when a $10 \mathrm{~s}$ rest period is introduced.

- The inclusion of rest periods has a significant effect on extending the fatigue life of binders.

Acknowledgments: The principal author would like to acknowledge the support of the Ministry of Higher Education and Scientific Research of Iraq and the Iraqi Cultural Attaché in London for the PhD scholarship.

Author Contributions: Ayad Subhy and Davide Lo Presti conceived and designed the experiments; Ayad Subhy performed the experiments; Ayad Subhy analyzed the data; Ayad Subhy and Davide Lo Presti contributed reagents/materials/analysis tools; Ayad Subhy wrote the paper.

Conflicts of Interest: The authors declare no conflict of interest.

\section{References}

1. Subhy, A.; Lo Presti, D.; Airey, G. Rubberised bitumen manufacturing assisted by rheological measurements. Road Mater. Pavement Des. 2016, 17, 290-310. [CrossRef]

2. Subhy, A.; Lo Presti, D.; Airey, G. An investigation on using pre-treated tyre rubber as a replacement of synthetic polymers for bitumen modification. Road Mater. Pavement Des. 2015, 16, 245-264. [CrossRef]

3. Lo Presti, D. Recycled tyre rubber modified bitumens for road asphalt mixtures: A literature review. Constr. Build. Mater. 2013, 49, 863-881. [CrossRef]

4. Huang, Y.; Bird, R.N.; Heidrich, O. A review of the use of recycled solid waste materials in asphalt pavements. Resour. Conserv. Recycl. 2007, 52, 58-73. [CrossRef]

5. Zhou, F.; Mogawer, W.; Li, H.; Andriescu, A.; Copeland, A. Evaluation of fatigue tests for characterizing asphalt binders. J. Mater. Civ. Eng. 2012, 25, 610-617. [CrossRef]

6. Bahia, H.U.; Hanson, D.; Zeng, M.; Zhai, H.; Khatri, M.; Anderson, R. Characterization of Modified Asphalt Binders in Superpave Mix Design; Transportation Research Board: Washington, DC, USA, 2001.

7. Tsai, B.-W.; Monismith, C.; Dunning, M.; Gibson, N.; D'Angelo, J.; Leahy, R.; King, G.; Christensen, D.; Anderson, D.; Davis, R. Influence of asphalt binder properties on the fatigue performance of asphalt concrete pavements. J. Assoc. Asph. Paving Technol. 2005, 74, 733-790.

8. Planche, J.-P.; Anderson, D.; Gauthier, G.; Le Hir, Y.M.; Martin, D. Evaluation of fatigue properties of bituminous binders. Mater. Struct. 2004, 37, 356-359. [CrossRef]

9. Chen, J.-S.; Tsai, C.-J. How good are linear viscoelastic properties of asphalt binder to predict rutting and fatigue cracking? J. Mater. Eng. Perform. 1999, 8, 443-449. [CrossRef]

10. Johnson, C.M.; Bahia, H.U.; Wen, H. Evaluation of Strain-Controlled Asphalt Binder Fatigue Testing in the Dynamic Shear Rheometer, 4th ed.; Int. Siiv Congress: Palermo, Italy, 2007.

11. Shen, S.; Airey, G.D.; Carpenter, S.H.; Huang, H. A dissipated energy approach to fatigue evaluation. Road Mater. Pavement Des. 2006, 7, 47-69. [CrossRef]

12. Pronk, A.; Hopman, P. Energy Dissipation: The Leading Factor of Fatigue; Thomas Telford Publishing: London, UK, 1991.

13. Van Dijk, W.; Visser, W. Energy Approach to Fatigue for Pavement Design. In Proceedings of the Association of Asphalt Paving Technologists, San Antonio, TX, USA, 21-23 February 1977.

14. Ghuzlan, K.A.; Carpenter, S.H. Energy-derived, damage-based failure criterion for fatigue testing. Transp. Res. Rec. J. Transp. Res. Board 2000, 1723, 141-149. [CrossRef]

15. Williams, D.; Little, D.; Lytton, R.; Kim, Y.; Kim, Y. Microdamage Healing in Asphalt and Asphalt Concrete, Volume II: Laboratory and Field Testing to Assess and Evaluate Microdamage and Microdamage Healing; The National Academies of Sciences, Engineering, and Medicine: Washington, DC, USA, 2001.

16. Little, D.N.; Lytton, R.L.; Chairl, B.; Williams, D.; Texas, A. An analysis of the mechanism of microdamage healing based on the application of micromechanics first principles of fracture and healing. Assoc. Asph. Paving Technol. 1998, 68, 501-542.

17. Kim, Y.-R.; Little, D.; Lytton, R. Fatigue and healing characterization of asphalt mixtures. J. Mater. Civ. Eng. 2003, 15, 75-83. [CrossRef]

18. Shen, S.; Chiu, H.-M.; Huang, H. Characterization of fatigue and healing in asphalt binders. J. Mater. Civ. Eng. 2010, 22, 846-852. [CrossRef] 
19. Glover, C.J.; Davison, R.R.; Bullin, J.A.; Estakhri, C.K.; Williamson, S.A.; Billiter, T.C.; Chipps, J.F.; Chun, J.S.; Juristyarini, P.; Leicht, S.E. A Comprehensive Laboratory and Field Study of High-Cure Crumb-Rubber Modified Asphalt Materials; The National Academies of Sciences, Engineering, and Medicine: Washington, DC, USA, 2000.

20. Rodríguez-Alloza, A.M.; Gallego, J.; Pérez, I. Study of the effect of four warm mix asphalt additives on bitumen modified with 15\% crumb rubber. Constr. Build. Mater. 2013, 43, 300-308. [CrossRef]

21. Akisetty, C.K.; Lee, S.-J.; Amirkhanian, S.N. Effects of compaction temperature on volumetric properties of rubberized mixes containing warm-mix additives. J. Mater. Civ. Eng. 2009, 21, 409-415. [CrossRef]

22. Zanzotto, L.; Kennepohl, G.J. Development of rubber and asphalt binders by depolymerization and devulcanization of scrap tires in asphalt. Transp. Res. Rec. J. Transp. Res. Board 1996, 1530, 51-58. [CrossRef]

23. Akisetty, C.; Xiao, F.; Gandhi, T.; Amirkhanian, S. Estimating correlations between rheological and engineering properties of rubberized asphalt concrete mixtures containing warm mix asphalt additive. Constr. Build. Mater. 2011, 25, 950-956. [CrossRef]

24. Billiter, T.; Davison, R.; Glover, C.; Bullin, J. Production of asphalt-rubber binders by high-cure conditions. Transp. Res. Rec. J. Transp. Res. Board 1997, 1586, 50-56. [CrossRef]

25. Attia, M.; Abdelrahman, M. Enhancing the performance of crumb rubber-modified binders through varying the interaction conditions. Int. J. Pavement Eng. 2009, 10, 423-434. [CrossRef]

26. Anderson, D.A.; Hir, Y.M.L.; Marasteanu, M.O.; Planche, J.-P.; Martin, D.; Gauthier, G. Evaluation of fatigue criteria for asphalt binders. Transp. Res. Rec. J. Transp. Res. Board 2001, 1766, 48-56. [CrossRef]

27. Di Benedetto, H.; De La Roche, C.; Baaj, H.; Pronk, A.; Lundström, R. Fatigue of bituminous mixtures. Mater. Struct. 2004, 37, 202-216. [CrossRef]

28. Tapsoba, N.; Sauzéat, C.; Benedetto, H.D. Analysis of fatigue test for bituminous mixtures. J. Mater. Civ. Eng. 2012, 25, 701-710. [CrossRef]

29. Lundstrom, R.; Di Benedetto, H.; Isacsson, U. Influence of asphalt mixture stiffness on fatigue failure. J. Mater. Civ. Eng. 2004, 16, 516-525. [CrossRef]

30. Carpenter, S.H.; Shen, S. Dissipated energy approach to study hot-mix asphalt healing in fatigue. Transp. Res. Rec. J. Transp. Res. Board 2006, 1970, 178-185. [CrossRef]

31. Shen, S.; Carpenter, S.H. Application of the dissipated energy concept in fatigue endurance limit testing. Transp. Res. Rec. J. Transp. Res. Board 2005, 1929, 165-173. [CrossRef]

32. Shen, S.; Carpenter, S.H. Dissipated Energy Concepts for HMA Performance: Fatigue and Healing; University of Illinois: Bloomington-Normal, IL, USA, 2007.

33. Pais, J.C.; Pereira, P.A.; Minhoto, M.J.; Fontes, L.; Kumar, D.; Silva, B. Application of plateau value to predict fatigue life. In Proceedings of the 2nd Workshop on Four-point Bending, University of Minho, Guimarães, Portugal, 24-25 September 2009.

34. Bhasin, A.; Castelo Branco, V.T.; Masad, E.; Little, D.N. Quantitative comParison of energy methods to characterize fatigue in asphalt materials. J. Mater. Civ. Eng. 2009, 21, 83-92. [CrossRef]

35. Boudabbous, M.; Millien, A.; Petit, C.; Neji, J. Shear test to evaluate the fatigue of asphalt materials. Road Mater. Pavement Des. 2013, 14, 86-104. [CrossRef]

(C) 2017 by the authors. Licensee MDPI, Basel, Switzerland. This article is an open access article distributed under the terms and conditions of the Creative Commons Attribution (CC BY) license (http:/ / creativecommons.org/licenses/by/4.0/). 